\title{
The use of electrical resistivity as a NDT for the specification of concrete durability
}

\author{
C. Andrade \\ Institute of Constriction Science "Eduardo Torroja", CSIC, Madrid, Spain \\ R. d'Andrea \\ Instituto Español del Cemento y stus Aplicaciones, España
}

\begin{abstract}
The calculation of the time to reinforcement corrosion and service life duration is a subject of increasing interest. In present communication is explained how to use the electrical resistivity to calculate both the initiation and propagation periods in the case of carbonation and chloride penetration, although only the case of chlorides is illustrated here. The main advantage is that resistivity is an inexpensive non destructive measurement that can be used for routine quality control. The resistivity is an indication of the porosity and pore connectivity. It increases with time as hydration proceeds which is an indication of aging or pore refinement. In addition to the measurement of the resistivity it is necessary to calculate a "reaction factor" for accounting of the binding with cement phases. Concerning the propagation period, the electrical resistivity is an indication of the moisture content of concrete and therefore, it has a relationship with the corrosion cement. A model is proposed in which the resistivity is introduced in the square root of time law.
\end{abstract}

\section{INTRODUCTION}

Regarding concrete durability Codes and Standards in general contain provisions reiated to: a) the concrete materials: cement, water, steel and aggregate types, concrete mix proportions, mechanical strength, b) the limit of dangerous substances, such as chlorides or sulphates, c) limitations to the crack width transversal to the reinforcement and d) the recommended cover thicknesses in function of exposure classes. However, there is an increasing demand to incorporate in to the current standards more advanced concepts related to concrete durability, die the need to better foresee and prevent distresses, in particular the corrosion of the reinforcement. Several proposals exist based in modelling the mechanisms of attack (Tuutti, 1982, Page et al. 1981) or in the so called "performance" concepts or the use of "durability indicators" (Baroghel-Bouny, 2002). Nevertheless, their effective incorporation into the standards seem to be slow and a worldwide controversy exists on which is the best approach, due to the lack of enough tradition and experience of these new proposals.

In present paper a proposal is presented that tries to be comprehensive by responding to the demand related to the introduction of performance parameters or durability indicators and that being suitable for quality control could also be applicable for modeling for predicting service life. The chosen durability parameter is the electrical resistivity of concrete (Andrade, 1993, Andrade et al. 2000, Monfore, 1968). Its basis and use for prediction is presented briefly applied to the corrosion of reinforcements and some examples are shown on the application of the model to several concrete mixes. The service life of reinforcements, $t$, is usually modeled by assuming two periods: the time to initiation of corrosion $t_{\text {and }}$ ands propagation, $t_{p}$. Thus, $t_{t}=t_{t}+t_{p}$. The calculation of the duration of $t_{f}$ is usually undertaken by considering that the aggressive penetrates through concrete cover by diffusion (Page et al. 1981) and therefore, Fick's law is used to calculate a Diffusion coefficient able to predict the concentration of the aggressive at a certain depth, at several periods of time, 
Providing that the aggressive threshold ( $\mathrm{pH}$-drop front in the case of carbonation or a certain chloride amount) is defined, the end of $t_{i}$ indicates the initiation of $t_{p}$. The initiation of corrosion established a limit state. The propagation period, $t_{p}$, is calculated by assuming a constant or averaged corrosion rate. In a similar manner than for $t_{i}$ the "limit state" or maximum corrosion has to be defined first in order to account for the length of the period. For the sake of present paper the corrosion onset will be considered for a chloride threshold value of $0.4 \%$ by cement weight. For the propagation period a single limit does not exist.

\section{MEASUREMENT OF RESISTIVITY}

It is a volumetric property that indicates the ability to the transport of electrical charges through the material. It is quantified through Ohm's law.

$$
R=\frac{V}{I}=\rho \frac{l}{A}
$$

where $R$ is the electrical resistance which can be measured applying a voltage and measuring the current cisculating $I$. The ratio between voltage and current is equal to the resistivity $\rho$ multiplied by a "geometric factor" $/ / A$ where $l=$ the distance between electrodes and $A$ is the cross section area.

The most common method is shown in Figure 1. Two electrodes as placed in two parallel faces of a concrete specimen and voltage is applied. The other common method is that known as "four points or Wenner method" shown right in the same figure.

\section{CONCRETE RESISTIVITY}

In a saturated concrete, its resistivity is higher as lower the porosity is as higher the mechanical strength. When the concrete is non saturated, the resistivity is higher as drier is the concrete.
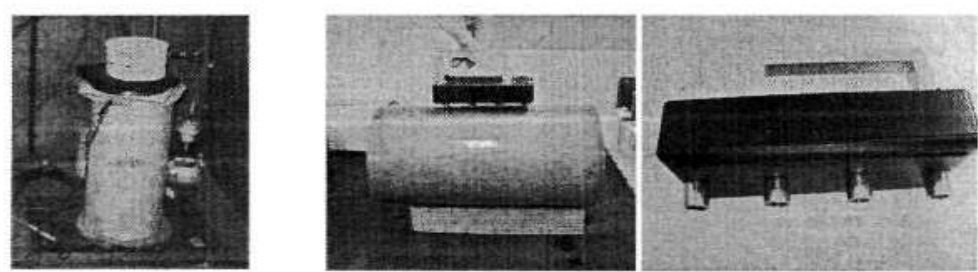

Figure 1. Left part: Direct method, Right part: Four point method and resistivimeter.

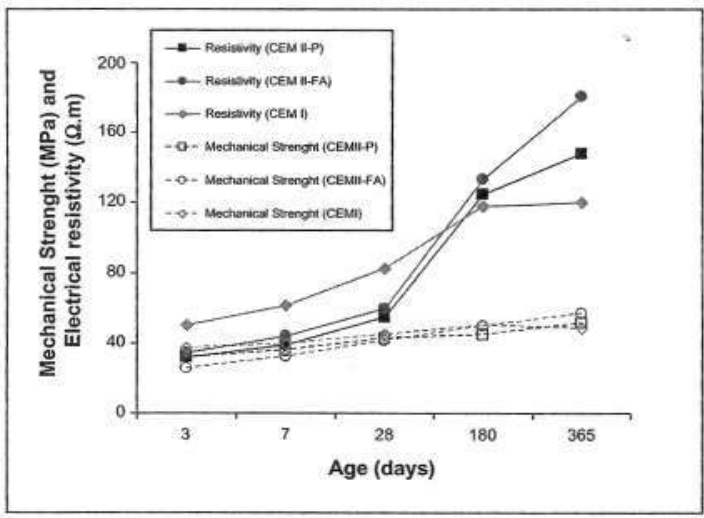

Figure 2. Evolution of resistivity and $f_{c}$ measured in some concrete samples. 


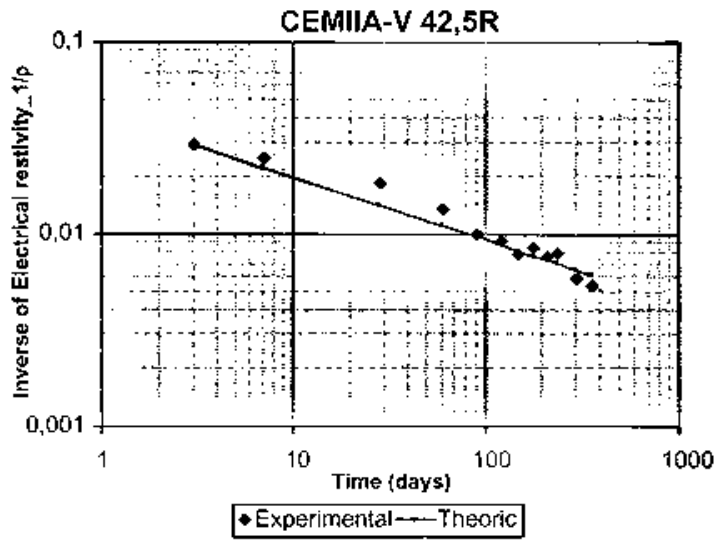

Figure 3. Representation of the inverse of the resitivity with time.

It is known that the resistivity of concrete increases with time due the refinement of the pore structure. This evolution is very similar to that of the increase of mechanical strength although some differences exist considering different cement types. The decrease in porosity with the advance of hydration leads to a lowering in porosity which is reflected in both mechanical strength and resistivity as is shown in Figure 2.

$$
\rho_{e s, 28 d}=\rho_{e s, t} \cdot \epsilon^{m t}
$$

The evolution of resistivity with time serves to quantify the "concrete aging". Thus if the inverse of resistivity is plotted in function of the time the above equation can be expressed as the following equation which is plotted in Figure 3. This law may have different power exponents for OPC than for blended cements. There are values in the literature (Andrade et al. 2005) and work is being done for its quantification.

$$
\rho(t)=\rho_{0}\left(t / t_{0}\right)^{+q}
$$

With respect to the influence of temperature, it has an important effect on resistivity, which only can be generalized if the $\rho$ values are standarized to a reference temperature that it is proposed to be $25^{\circ} \mathrm{C}$ (Andrade et al. 2000). An increase in temperature should increase diffusivity, $D$, and corrosion rate, $V_{\text {rarr }}$, however this increase in temperature may at the same time may produce an evaporation, which in turn would effect on the opposite in both, $D$ and $V_{\text {carr }}$. Therefore, the incorporation of temperature effects on models is, by large, still very seldom. In present case, it is incorporated by suggesting to measure $\rho_{e s, 28 d}$ at $25^{\circ} \mathrm{C}$. The standardization of resistivity from other temperatures has been explained by Castellote et al. (2002).

Regarding the influence of the chemical composition of pore solution, its impact in the total resistivity is small providing the concrete remains alkaline. At high $\mathrm{pH}$ values the pore solution resistivity varies from $30-100 \Omega \mathrm{cm}$, which is comparatively very small taking into account that the concrete resistivity after several days of hardening is in the range of severa] hundreds $\Omega \cdot \mathrm{cm}$. When concrete carbonates, then the pore solution is much more diluted and the electrical resistivity of the pore solution may significantly increase and start to be influencing the volumetric value. In chloride contaminated concrete, the chlorides lowers the concrete resistivity but not too much (it can decrease to half value of that without chlorides), as the resistivity of an alkaline solution is not lowered very much by the presence of chlorides. 


\subsection{Resistivity and diffusivity}

The ability of resistivity to quantify diffusivity is based in one of the Einstein's law which relate the movement of electrical charges to the conductivity of the mediun (Andrade, 1993):

$$
D_{e}=\frac{k_{C I}}{\rho_{e s}}=k_{C l} \sigma
$$

where $D_{\varepsilon}=$ effective diffusion coefficient, $k_{C}$ is a factor, which depends on the external ionic concentration, $\rho_{e s}$ is the resistivity (in this case of concrete saturated of water) and $\sigma$ the conductivity (inverse of resistivity). A value of $k_{C l}$ of $20 \times 10^{-5}$ can be used for external chloride concentrations of 0.5 to $1 \mathrm{M}$.

However, this expression only account for the transport of the chloride ions and then, the chloride binding has to be taken into account. This is proposed by means of introducing a new factor, $\left(r_{c}=\right.$ reaction or binding factor $)$. This reaction factor is a "retarder" of the penetration of chlorides. Above equation maintains its mathematical structure but can be now written, where $\rho_{a s}$, is an "apparent" electrical resistivity in saturated conditions:

$$
D_{C l}=\frac{k_{C l}}{\rho_{e s} \cdot r_{C l}}
$$

This equation also can be applied to the case of carbonation. This is due to carbonation progresses when the concrete is partially dry. That is, as higher is the porosity higher will be the carbonation depth. As said, porosity is appraised by measuring the electrical resistivity. Therefore, equation can be also applied to carbonation providing another constant $k_{\mathrm{CO}_{2}}$ is considered for the atmospheric exposure. In addition, in a similar manner than for chlorides a reaction factor, $\mathrm{CO}_{2}$, taking into account the amount of alkaline material able to bind $\mathrm{CO}_{2}$, has to be introduced:

$$
D_{\mathrm{CO}_{2}}=\frac{k_{\mathrm{CO}_{2}}}{\rho_{\mathrm{es}} \cdot r_{\mathrm{CO}_{2}}}
$$

Thus, expressions of the diffusion coefficients of chlorides and carbon dioxide in terms of the apparent electrical resistivity, $\rho_{u s}$, in saturated concrete have been dediced.

\section{SERVICE LIFE MODEL BASED ON CONCRETE RESISTIVITY}

In order to predict the corrosion onset it is necessary to have an equation in which the resistivity could be the rate determining parameter in function of the time. The simplest equation is the so named "square root of time". Assuming a square root relation between penetration of the aggressive front and time $x_{i}=V_{\mathrm{CO}_{2}, \mathrm{Cl}} \sqrt{t}$, the factor of relation $V$ represenis the ease or veiocity of penetration, $\mathrm{V}_{\mathrm{Cl}, \mathrm{CO}_{2}}$ and therefore the service life can be written in the form:

$$
t_{l}=t_{i}+t_{p}=\frac{x_{i}^{2}}{V_{\mathrm{CO}_{2}, \mathrm{Cl}}}+\frac{P_{x}}{V_{c o r r}}
$$

To relate $\mathrm{V}_{\mathrm{Cl}, \mathrm{CO}_{2}}$ to the resistivity can be made through another of Einstein equations when explaining the random walk of an ion in an electrolyte (Andrade, 1993):

$$
x=\sqrt{ } 2 D t
$$

which indicates that $V_{C l, C O}=\sqrt{2} \mathrm{D}$ and therefore equal to $\sqrt{2} k_{\mathrm{Cl}_{1} \mathrm{CO}_{2}} / \rho_{\mathrm{es}} r_{\mathrm{Cl}, \mathrm{CO}}$. Rearranging this expression it results for the initiation period the following equation:

$$
t_{i}=\frac{x_{i}^{2} \cdot \rho_{e s} \cdot r_{C l, C O_{2}}}{2 \cdot k_{C l, C O_{2}}}
$$


In order to calculate the propagation period, it has been found a relation between corrosion rate and electrical resistivity of:

$$
Y_{\text {corr }}=\frac{k_{\text {corr }}}{\rho_{e f}}
$$

where $k_{\text {corr }}$ is a constant with a value of $3 \times 10^{4} \mu \mathrm{A} / \mathrm{cm}^{2} \cdot \mathrm{k} \Omega \cdot \mathrm{cm}$

The resistivity, $\rho_{c i}$, in this case is that of the concrete at its actual degree of saturation and therefore can be that of water saturated conditions or nol. In order to calculate the $t_{p}$, it can be assumed a certain year averaged concrete moisture content in each exposure class and in function of it, averaged $I_{c}$ and $\rho$ values can be attributed to each one (considering both moisture and temperature). Then the lotal service life is expressed:

$$
t_{l}=t_{i}+t_{p}=\frac{x^{2} \rho_{e s} r_{C l, C O_{2}}}{k_{C l, C O_{2}}}+\frac{P_{x} \cdot \rho_{e f}}{k_{c o r r}}
$$

The main parameter in this equation is the concrete resistivity measured in saturated conditions, and at $25^{\circ} \mathrm{C}: \rho_{c s}$, at 28 days of life, and $\rho_{e f}$ given as year averaged value for certain exposure conditions.

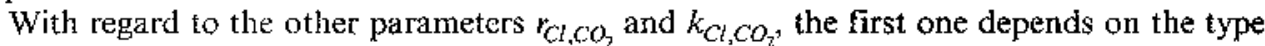
and amount of cement and therefore, to the extension of reaction of the penetrating substance with cement phases. In Table 1 are given some typical values.

The values of $k_{C t, C O}$, are given in Table 2 in function of the environmental concentration of aggressive (exposure class).

\subsection{Example of application}

Assuming a concrete with a cover depth of $5 \mathrm{~cm}$ fabricated with a cement type II/A to be placed in an exposure class type IIIb for a service life of 100 years, in Table 3 are given the

Table 1. Values of the reaction or retarder factor for 3 types of cement.

\begin{tabular}{lcl}
\hline Cement & $r_{G}$ & Standard deviation \\
\hline I & 1.9 & 1.3 \\
I + silica furne & 1.5 & 0.5 \\
IIA & 3.0 & 2.1 \\
\hline
\end{tabular}

Table 2. Values of ambient factor following the exposure classification of EN206.

\begin{tabular}{lc}
\hline Exposure class & $K_{C}\left(\mathrm{~cm}^{3} \Omega /\right.$ year $)$ \\
\hline X0 & 200 \\
XC1 & 1000 \\
XC3 & 3000 \\
XS1 (d $>500 \mathrm{~m}$ from the coast) & 5000 \\
XSI (d < 500 m from the coast) & 10,000 \\
XS2 & 17,000 \\
XS3 & 25,000 \\
\hline
\end{tabular}

Table 3. Example of calculation of the needed resistivity.

\begin{tabular}{ll}
\hline Cement type II/A & $r_{C}=1.8$ \\
\hline Exposure class (XS2) & $K\left(\mathrm{~cm}^{2}\right.$ W/year) $=17,000$ \\
Life Time & $t$ (years) $=100$ \\
Cover depth & $X_{C I}(\mathrm{~cm})=5$ \\
Aging factor during 10 years & $q=0.3$ \\
\hline
\end{tabular}


values of the reaction and ambient, as well as the aging factors. The calculation gives that the resistivity at 28 days needed is of $87.6 \Omega \mathrm{m}$.

$$
5=\sqrt{\frac{17,000}{\rho_{0}\left(\frac{10}{0.0767}\right)^{0.3} \cdot 1.8}}-\sqrt{100}\left\{\rho_{0}(\Omega \cdot \mathrm{cm})=8760 \rightarrow \rho_{0}(\Omega \cdot m)=87.6\right.
$$

\section{FINAL COMMENTS AND CONCLUSIONS}

The need to provide concrete with target durability has stimulated the development of models to predict service life. These models are based in paramcters figuring concrete permeation on resistance to penetration. In general, diffusion cocfficient derived from analytical solutions to differential equations as the reproduction of real boundary and initial conditions of the differential equations is not obvious or easy.

The method here presented is based in the use of a NDT as resistivity is to predict the service life. The use of resistivity is based in Einstein law relating electrical resistance or conductance with the diffusion coefficient. Making cerlain assumptions this basic law can be applied to the advance of carbonation front or chloride threshold, and to the representation of steel corrosion progression. The general expression of service life is:

$$
t_{l}=t_{i}+t_{p}=\frac{x^{2} \cdot \rho_{e s} \cdot s_{C l, C_{2}}}{k_{C l, C O_{2}}}+\frac{P_{x} \rho_{e f}}{k_{c o r r}}
$$

This model can be used for calculating cover thicknesses from actual resistivity values or the minimum resistivity for a certain cover thickness. Resistivity can be as well used as a performance parameter to be fulfilled by standard specimens at a certain age or as durability and corrosion indicator. Being the measurement of resistivity a non destructive method, it can be as well used for on-site quality control.

\section{REFERENCES}

Andrade, C. 1993. Calculation of chloride diffusion coefficients in concrete from ionic migration measurements. Cement and Concrete Research. 23: 724-742.

Andrade, C., Alonso, C., Arteaga, A. \& Tanner, P. 2000. Methodology based on the electrical resistivity for the calculation of reinforcement service life. 5 th Canmet/ACI Int. Conference on Durability of concrete-Supplementary papers volume: 899-915. Barcelona.

Andrade, C., Castillo, A., Rio, R. \& d'Andrea, R. 2005. Empirical relation between electrical resistivity and compression strength of cilindrical specimens of concrete made with different cement types. $47^{\circ}$ Congreso Brasilero do Concreto. CBC-2005, September 2005.

Baroghel-Bouny, V. 2002. Which toolkit for durability evaluation as regards chloride ingress into concrete? Part II: Development of a performance approach based on durability indicators and monitoring parameters. In C. Andrade and J. Kropp (eds). Proceedings of the 3rd Internationat Workshop "Testing and modelling chloride ingress into concrete", Madrid.

Castellote, M., Andrade, C. \& Alonso, C. 2002. Standardization, to a reference of $25^{\circ} \mathrm{C}$, of the electrical resistivity values measured at any temperature for nortars and concrete in saturated conditions. $A C I$ Materials Journal. $99(2) ; 119-128$.

Monfore, G.E. 1968. The electrical resistivity of concrete. Journal of PCA: 35-48.

Page, C.L., Short, N.R. \& El Tarras, A. 1981. Diffusion of Chloride lons In Hardened Cennent Pastes. Cement and Concrete Research. 11(3): 395-406.

Tuutti, K. 1982. Corrosion of Steel in Concrete, Swedish Cement and Concrete Research Institute (CBI) No. 4-82, Stockholm. 